\title{
The Paradigm Wars: Is MMR Really a Solution?
}

\section{Ryan Thomas Williams}

School of Social Sciences, Humanities and Law, Teesside University, Middlesbrough, Tees Valley, TS1 3BX, United Kingdom

E-mail for correspondence: ryan.williams@tees.ac.uk

\begin{abstract}
Educational research has several competing views of the social sciences, and these are often referred to as paradigms. Hammersley $(2013$, p. 13$)$ portrays paradigms as 'not simply methodologies; they are ways of looking at the world, different assumptions about what the world is like and how we can understand or know about it'. The paradigm wars' boils down to a simple conflict between academics and scholars of qualitative and quantitative research which concerns the relative merits of the different perspectives. In the 1980s, the objectivity-seeking quantitative researcher diminished, whilst, post positivists, interpretivists and critical theorists flourished throughout this same period. Mixed methods research (MMR) combines elements of both qualitative and quantitative approaches and has often been branded as a 'transformative paradigm'. The importance of MMR means that the author can combine knowledge sets and move away from one's allegiance to a particular research perspective. This review of literature will examine the paradigms that are commonly associated with education research. There is an active debate in the research community on the paradigms wars, and this will also be examined in relation to MMR.
\end{abstract}

Keywords: MMR, Paradigm wars, Educational research

\section{INTRODUCTION}

Educational research has several competing views of the social sciences, and these are often referred to as paradigms. Hammersley $(2013$, p. 13) portrays paradigms as 'not simply methodologies; they are ways of looking at the world, different assumptions about what the world is like and how we can understand or know about it'. In other words, a paradigm is a way of pursuing knowledge through a shared set of beliefs and principles (Hammersley 2013; Kuhn 1962). Paradigms can be summarized by the three following fundamental questions, 1) the ontological question, 2) the epistemological question, and 3) the methodological question.

Lukenchuk (2013) argues that the term 'paradigm' was popularized and given a contemporary meaning by the theorist Thomas Kuhn (1970) when he adopted the word to refer to a set of practices and beliefs that define a scientific discipline. A fundamental characteristic of paradigms is that they are significant in underpinning researchers' approaches to methodologies. However, as more knowledge is assimilated it is possible to challenge existing paradigms and make a 'paradigm shift'. Cohen,
Manion \& Morrison (2018, p. 8) describes one of the most notable examples is the old paradigm that Earth is placed at the Centre of the universe, only to be replaced by the Copernican heliocentric model through the scientific revolution period. Simply put, the science of their day could not describe what the scientists could observe. Prior to Kuhn (1970), positivism and the concept of objective reality only existing if elements are available for observation was widely accepted. Kuhn (1970) challenged the processes derived with knowledge from empirical evidence, and instead recognized the 'social and cultural character of research' for cumulative research. Kuhn (1970) as cited in Hammersley (2013, p. 39) argued that rather than natural science research 'gradually accumulating, with errors being corrected and new discoveries adding to further knowledge...processes are discontinuous, punctuated by paradigmatic revolutions involving disagreement that cannot be resolved at the time of rational means', for example, the move from Newtonian physics to $21^{\text {st }}$ century physics. In contrast, social science research must have independent actors and social worlds in order for social construction of it to make sense. 
Guba \& Lincoln (1994) argue that paradigms as a world view guide a researcher, not only in choices of methods, but in ontological and epistemological ways. This allows the author to confront complex and important issues of ethics, ontology, epistemology and methodology before giving a concrete shape to research.

Rather than paradigms driving the research, they provide clarity on the purpose and nature of research and help to organize thinking about the research (Cohen, Manion \& Morrison 2018). Nevertheless, paradigms are not unproblematic concepts, for example, there are many variations that lie within each paradigm, as well as characteristics that overlap the different types, and thus it was important for the author to understand traditional boundary lines. Social science researchers and theorists (Denzin \& Lincoln 2002; Denzin \& Lincoln 2005) have argued that the boundary lines separating the paradigms and perspectives have begun to blur, especially within the last decade. Despite this, the following section will set out the four paradigms commonly accepted in education research: positivism, post positivism, interpretivist and critical theory.

\section{Positivism}

The characteristics of positivism reveal that social phenomena can be researched in a similar fashion to that in natural sciences through empirical investigation. This position argues that genuine knowledge must be based on sensory experiences (Oldroyd 1986; Hammersley 2013; Pring 2015; Beck 1979; Cohen, Manion \& Morrison 2018). The approach abandons attempts to gain knowledge by reason alone, and instead reveals that social facts must be evidenced empirically (Beck 1979). Although, there is an emphasis on observational evidence, operationalism, and scientific method, Hammersley (2013) argues that positivism is not exclusive to quantitative approaches and can be equally embraced in qualitative data.

Positivism analysis has been described as 'laws or law-like' generalizations by researchers (Cohen, Manion \& Morrison 2017 \& 2018; Hammersley 2013) due to the importance of natural science in the methodological procedures. Notwithstanding, positivism is less successful with research that involves human behaviors, and this is largely due to the intangibility of the phenomena and complexity of human nature (Cohen, Manion \& Morrison 2018). Whereas, positivism regards human behavior as regular, predictable and not social, fluid nor dependent on a set of circumstances. In other words, studies that involve human interaction such as teaching and learning present positivists' researchers with challenges, and therefore is particularly relevant in the present research.

There are four assumptions that underpin positivism and these are 1) determinism, 2) empiricism, 3) parsimony, and 4) generality. Firstly, determinism is the assumption that events have causes and the natural world is determined by circumstances. Additionally, Cohen, Manion \& Morrison (2018) argue that determinism not only proceeds on the belief that there are casual links in determining events, but there is a regularity in about the way they are determined. To put it more simply, laws account for what is happening in the world, making it predictable rather than 'capriciously'. Secondly, empiricism is the assumption that reliable knowledge can only be derived from experiences, such as observations. Cohen, Manion \& Morrison (2018, p. 11) clarifies what this means in practice:

In practice, empiricism means scientifically that the tenability of a theory or hypothesis depends on the nature of the empirical evidence for its support. Empirical means which is verifiable by observation, direct experience and evidence, data-yielding proof or strong confirmation, in probability terms of a theory or hypothesis in a research setting

Thirdly, parsimony is the assumption that the phenomena should be explained simplistically rather than in complex terms, and this is particularly critical when discussing theory development. Allen (2018) explains that when competing theories exists with the same predictive power, the simplistic theory or the theory with the fewest number of assumptions is preferred as it reduces risks and errors. For instance, as with Occam's razor, explanatory principles should not be needlessly multiplied (Cohen, Manion and Morrison 2018). Parsimony is relevant in both quantitative (as with deleting unnecessary measures or combining variables to create a measure) and qualitative research (as with limiting the number of themes), therefore is relevant in the present research.

Finally, generality is the assumption that there is a relationship between the abstract and the particular. Kerlinger (1970) argues that scientists are set up to generalize their findings to the world in order to support their explanations. This means that social scientists require large sample sizes and must 'exercise great caution when generalizing their findings to the population' (Cohen, Manion \& Morrison 2018, p.11).

Despite the benefits and successes of positivism, there are sections within the literature that are concentrated to the criticisms of positivism (as in Kettley 2012; Douglas 2004). Essentially, criticisms are focused on how positivism 'dehumanizes life and mind' and values life in measurable terms rather than 'inner experience' (Nesfield-Cookson 1987). Ions (1977) argues that statistical theory and method are ways of quantifying human acts and this runs the risks the depersonalization. Ions (1977) concludes that quantifying isn't necessarily negative per se, but objects to it as an end act that replaces humane studies on human conditions. Likewise, this is in agreement with Horkheimer's (1972) and Rozak's (1970 \& 1972) earlier work that argued science in the pursuit of objectivity is isolated away from our true self. Another collective criticism is levelled at positivism in social science which fails to take into account an individual's unique ability to 
interpret experiences (Pring 2015). In other words, how each human understands and experiences the world is different and this has to be recognized in the social world, away from objectivism.

Unlike natural sciences, social science is a subject-subject relation in which the meanings that the subjects hold are part of their construction of the world (Giddens 1976). The difficulty with positivism is that it ignores the profound differences of social science and natural science, and by regarding human behavior as passive and controlled there is no scope for intention, individualism and freedom (Chomsky 1959 as cited in Cohen, Manion \& Morrison 2018). In conclusion, scientific experimentation that appears to control variables and simplify the social world through quantification is more likely to provide an artificial deterministic view of the world (as in Layder 1995; Cohen, Manion \& Morrison 2018; Pring 2015; Horkheimer 1972).

\section{Alternative Research Paradigms}

Positivists view the world through the lens of a controllable, objective and standardized universe that suggests there are predictable effects to causes. Despite this scientific method, some scholars have rejected the positivist view in favor of alternative paradigms, each with their own epistemological viewpoint. Some of the most researched paradigms in social sciences include: postpositivism, interpretivism and critical theory.

Post-positivists embrace scientific theory and rationalism, yet acknowledge that there are multiple interpretations of a world view. Popper (1968 \& 1980) argues that the world is multi-layered and must be able to tolerate multiple interpretations. The world is viewed as multi-layered as a result of the different values, perceptions and theories that underpin empiricism, for example as in observations. Simply put, generalization is the goal of positivism but is not in post-positivism since knowledge is subjective. Additionally, post positivists' researchers (Popper 1968 \& 1980; Reichardt \& Rallis 1994; Nisbett 2005; Philips and Burbules 2000) argue that certain 'facts' are often 'valueladen', which means the interpretation are determined by underlying theories. The present research is studied through the lens of Trowler's (2008) socio-cultural theory with the concept of social interactions being important for learning as an underlying theoretical approach. An example of this is illustrated in Cohen, Manion and Morrison (2018, p. 16-17).

Imagine that a researcher observes a class lesson and notices one student winking at the teacher. Is this student being cheeky (a theory of deviant or challenging behavior), a sign of understanding (a theory of cognition/recognition), a physical problem (Tourette's syndrome), a sign of stress or happiness (a theory of emotional behavior), a sign of friendliness (a theory of interpersonal non- verbal behavior), or what? The observation on its own cannot tell us. There is a gap between an observed phenomenon and the explanation or theory of, or a hypothesis about, the phenomenon.

This example supports post-positivists' claims that observations cannot and should not count as evidence alone, without additional help from non-sensory experience such as the researcher's viewpoints (Philips and Burbules 2000). This emphasizes the importance of using Trowler's (2008) socio-cultural theory as a theoretical position. Viewing the world as a post-positivist acknowledges that the world is problematic, whilst arguing that scientific method can present research value if 'reformulated' with theory-laden nature (Cohen, Manion and Morrison 2018).

Most objections to positivism is a common belief that human behavior is not governed by universal laws, and this view has been highly commented on in the literature from Beck (1979) to Creswell (2013). More specifically, there is a viewpoint that due to the importance of theoretical frameworks, it is not possible to achieve true objectivity (Guba 1990). An interpretivist paradigm assumes that knowledge and meaning are constructed by both the participants and observers, with scholars such as Moschkovich (2019) describing naturalism as in effect, accepting that there are multiple realities. These multiple versions of reality are shaped by the multiple theoretical and value frameworks (Guba 1990). According to Guba (1990, p.26) and Erlandson (1993), the goal of interpretivist research is 'to identify the variety of constructions that exist and bring them into as much consensus as possible'. In order to fulfil the goal, an interpretivist stance must take a holistic view in understanding the participants' interpretation of the world, i.e. social reality as defined by the participants. The differences in methods between positivists and interpretivists paradigms are illustrated in table 1 below.

Table 1: The differences between a positivist and naturalist paradigm

\begin{tabular}{|l|l|}
\hline Positivism & Interpretivism \\
\hline One real world & Multiple realities \\
\hline Seeks generalisations & Seeks patterns \\
\hline $\begin{array}{l}\text { Objective and } \\
\text { quantifiable }\end{array}$ & $\begin{array}{l}\text { Subjective and non- } \\
\text { quantifiable }\end{array}$ \\
\hline $\begin{array}{l}\text { Usually measured- } \\
\text { statistical analysis }\end{array}$ & Qualitative analysis \\
\hline Researcher verification & $\begin{array}{l}\text { Participant verification } \\
\text { grounded on interpretations }\end{array}$ \\
\hline
\end{tabular}

In other words, interpretivism is concerned with the 'how' and 'why' of a phenomenon, whereas positivism is focused on the absolute. Some scholars argue that interpretivism and post-positivism 'abandon' scientific procedures needed for useful generalizations of behavior (Cohen, Manion \& Morrison 2017, 2018). A common example of this in education is if a teacher perceives a pupil to be of low ability, they will act as if that pupil is low ability, but 
in fact, the teacher's perception is wrong and the pupil of high ability and require more challenging tasks. Conversely, a different teacher may have an alternative perception of the pupil, thus subjective reports are often misleading (Berstein 1974). A more scientific method or positivist approach would be to look at previous assessment scores.

\section{PARADIGM WARS}

A particular research phenomena often dictates the methodology that is used to seek the question or problem. There is much concentration on the 'what' when discussing research methodologies as opposed to the 'why'. Oakley (1999) argues that there are underlying reasons that dictate a choice of methodology that go beyond the research question, more specifically, philosophies, and long-held epistemological views on social science research. Thus, a methodological decision is often affected by the paradigm lens and social context. There are two different positions on this debate and these are: 1) quantitative and 2) qualitative.

Schwandt (2000, p.189) argues that 'qualitative enquiry practitioners share a general rejection of the blend of scientism, foundational epistemology, instrumental reasoning, and the philosophical anthropology of disengagement that has marked mainstream social sciences', meaning that qualitative approaches help in addressing the 'why and how' of a particular research phenomenon. According to Denzin \& Lincoln (1994, p.2), qualitative research is 'multi-method in focus' that involves the collection of a variety of materials such as 'case study, personal experience, introspective life story, interview, observational, historical, interactional and visual texts that describe routine and problematic moments in individuals' lives'. In application, qualitative research has shown to be used by scholars to move thinking beyond progressive political action and into methods that connect pedagogy and ethics with to action in the real world' (see Denzin \& Lincoln 2005, p.5). Despite the term 'qualitative' has been associated with processes that are not rigorously examined or measured in terms of quantity or intensity, qualitative research is well developed in terms of validity and reliability (Kirk \& Miller 1986). Contrastingly, quantitative research emphasizes that measurement and analysis of causal relationships between variables, not processes (Denzin \& Lincoln 1994). Quantitative studies are largely dependent on tests and ratings, such as questionnaires, scales, and physical measures. Therefore, it can be concluded that while numbers are the end product of quantitative researcher, the narrative description of events are the end result of qualitative (Strauss \& Corbin 1990).

Historically, there has been a heavy emphasis on quantification in the sciences, for instance Mathematics is often described as the 'queen of sciences'(see Guba \& Lincoln 1994), whereas less quantifiable sciences, such as biology is referred to as 'soft', which gives the impression it is less dependable than physics or chemistry. During the 1960s, an emergence of social science researchers critiquing quantitative methods was highly visible in the literature (see Bryman 1988; Cicourel 1964; Rose 2007), consequently there became an appetite for collecting social science data in other forms, i.e. qualitatively (Oakley 1999; Hammersley 1989). Despite the validity and importance of both types of research, the different epistemological and ontological positions has punctuated research capacity and academic development. This philosophical discourse has led rise to the term 'paradigm wars' with some academic commentators using war-like terminology to describe positions, such as 'enemies', 'opposing armies', and 'treat former enemies with suspicion' (see Bryman 2006; Griffiths 2013). Essentially, the 'paradigm wars' boils down to a simple conflict between academics and scholars of qualitative and quantitative research which concerns the relative merits of the different perspectives. In the 1980s, the objectivity-seeking quantitative researcher diminished, whilst, post positivists, interpretivists and critical theorists flourished throughout this same period (see Gage 1989; Griffiths and Norman 2011). In education, using scientific method to improve teaching had not 'paid off' and researchers began arguing that human affairs cannot be studied with the same scientific methods used to study the natural world (Gage 1989). Scholars have argued that qualitative methods might yield insights that searching for predictions does not. It is thought that studies should recognize the complexity of science and philosophy not being inextricably linked (Hammersley 2013). In 2006, Bryman declared that 'the war was over', however, Griffiths (2013 p. 584) points out that hostility has not 'ceased on all fronts' and this is evidenced by present day research publications promoting new frameworks and guidance to end the paradigm wars.

Interestingly, a new line of research has emerged through this last decade, mixed methods, which integrates quantitative and qualitative data in a single project, resolving the issue. Mixed methods argue for their compatibility or at least their ability to live alongside each other and to work together to solve a problem. Reams \& Twale (2008, p.133) further argue that mixed methods are necessary and important in addressing information and perspectives, and that they 'increase collaboration of data, render less bias and more accurate conclusions'. The rise of mixed methods research demonstrates that there is an interest in embracing varied approaches to collecting and analyzing data in the social sciences. Polio (2012) argues that as more researchers begin to talk about her purpose of the research rather than the paradigm, it opens the door for mixing orientations and could be a way to move 'beyond the paradigm wars' (p. 294), and this is particularly relevant in the present research. However, Polio (2012) does add caution in respect of how little has actually changed in many academic disciplines and urges qualitative researchers to once again embrace the concept 
of paradigms and 'reclaim the paradigmatic stance' and work towards integrating these elements with work that complement other paradigms. Guba \& Lincoln (1994) affirm that both qualitative and quantitative methods may be used appropriately with any research paradigm, though interpretivist and critical theory paradigms are central to qualitative research. In conclusion, researchers need not become mired in the paradigm debate; 'as long as we know what we are dealing with in mixed methods research then this may suffice' (Cohen, Manion \& Morrison 2018).

\section{CONCLUSION}

The purpose of this review was to support a better understanding of the paradigm wars and the notion of mixed methods research being a transformative paradigm to end the wars. When the author was establishing a paradigmatic stance for the wider research project, it was surprising that commentary is much immersed in this area today. Along with this, conflict between qualitative and quantitative researchers go back to the 1970s. Mixed methods as a model for research is emerging and has been lauded by modern day scholars. This movement appears to have diluted tensions of the paradigm wars in relation to pragmatism. This may subsequently lead to enhanced collaboration between researchers, and render less bias in conclusions. At the very least, MMR opens the door for mixing orientations in research. This is particularly useful for the author's thesis as it helps organize information and understand our world. Paradigms also affect the way we design, record, and interpret our experiments and observations, as social scientists.

\section{REFERENCES}

Allen, D. (2018). Translational mobilisation theory: a new paradigm for understanding the organisational elements of nursing work. International journal of nursing studies, 79, 36-42.

Beck, R. N. (1979). Handbook in Social Philosophy. New York: Macmillan.

Bernstein, B. (1974). Sociology and the sociology of education: a brief account. In J. Rex (ed.) Approaches to Sociology: An Introduction to Major Trends in British Sociology.

Bryman, A., Bresnen, M., Beardsworth, A., \& Keil, T. (1988). Qualitative research and the study of leadership. Human relations, 41(1), 13-29.

Bryman, A. (2006). Paradigm peace and the implications for quality. International journal of social research methodology, 9(2), 111-126.

Cicourel, A. V. (1964). Method and measurement in sociology.

Cohen, L., Manion, L., \& Morrison, K. (2018). Research methods in education. routledge.

Denzin, N. K., \& Lincoln, Y. S. (Eds.). (1994). Handbook of qualitative research. Sage Publications, Inc.

Denzin, N. K., \& Lincoln, Y. S. (2002). The qualitative inquiry reader. Sage.
Denzin, N. K., \& Lincoln, Y. S. (2005). Introduction: The discipline and practice of qualitative research.

Gage, N. L. (1989). The paradigm wars and their aftermath a "historical" sketch of research on teaching since 1989. Educational researcher, 18(7), 4-10.

Giddens, A. (1976). Classical social theory and the origins of modern sociology. American Journal of Sociology, 81(4), 703-729.

Griffiths, P., \& Norman, I. (2011). What is a nursing research journal?.

Guba, E. (1990) The Alternative Paradigm Dialogue. In Guba, E. (Ed.) The Paradigm Dialogue. London, Sage.

Guba, E. G., \& Lincoln, Y. S. (1994). Competing paradigms in qualitative research. Handbook of qualitative research, 2(163-194), 105.

Hammersley, M. (2013). What Is Qualitative Research? London: Bloomsbury Academic.

Horkheimer, M. (1972). Critical theory: Selected essays (Vol. 1). A\&C Black.

Ions, E. S. (1977). Against behaviouralism: A critique of behavioural science.

Kerlinger, F. N. (1970). Foundations of Behavioral Research. New York: Holt, Rinehart \& Winston.

Kettley, N. (2012). Theory Building in Educational Research. London: Continuum Books.

Kirk, J. and Miller, M. L. (1986). Reliability and Validity in Qualitative Research. Qualitative Research Methods Series, no. 1. Beverly Hills, CA: Sage.

Kuhn, T. S. (1970). Criticism and the growth of knowledge: Volume 4: Proceedings of the International Colloquium in the Philosophy of Science, London, 1965 (Vol. 4). Cambridge University Press.

Kuhn, T. S. (1962). The Structure of Scientific Revolutions. Chicago, IL: University of Chicago Press.

Layder, D. (1994). Understanding Social Theory. London: Sage.

Moschkovich, J. N. (2019). A Naturalistic Paradigm: An Introduction to Using Ethnographic Methods for Research in Mathematics Education. Compendium for Early Career Researchers in Mathematics Education, 59.

Nesfield-Cookson, B. (1987). William Blake: Prophet of Universal Brotherhood. London: Crucible.

Oakley, A. (1999). Paradigm wars: some thoughts on a personal and public trajectory. International Journal of Social Research Methodology, 2 (3), pp. 247- 54.

Oldroyd, D. (1986). The Arch of Knowledge: An Introductory Study of the History of the Philosophy and Methodology of Science. New York: Methuen.

Phillips, D. C. and Burbules, N. C. (2000). Postpositivism and Educational Research. Lanham, MD: Rowman \& Littlefield Publishers.

Popper, K. (1968). The Logic of Scientific Discovery (second edition). London: Hutchinson. Popper, K. (1980) Conjectures and Refutations (third edition). London: Routledge \& Kegan Paul.

Pring, R. (2015). Philosophy of Educational Research (third edition). London: Bloomsbury Academic. 
Reams, P., and Twale, D. (2008). The promise of mixed methods: discovering conflicting realities in the data. International Journal of Research and Method in Education, 31 (2), pp. 133-42.

Reichardt, C. S. and Rallis, S. F. (1994). Qualitative and quantitative inquiries are not incompatible: a call for a new partnership. In C. S. Reichardt and S. F. Rallis (eds) The Qualitative- Quantitative Debate: New Perspectives. San Francisco, pp. 85- 92.

Rose, G. (2007). Visual Methodologies (second edition). London: Sage.

Roszak, T. (1970). The Making of a Counter Culture. London: Faber \& Faber.

Roszak, T. (1972). Where the Wasteland Ends. London: Faber \& Faber.

Schwandt, T.A. (2000). Three epistemological stances for qualitative inquiry: Interpretivism, hermeneutics and social constructivism.
Strauss, A., \& Corbin, J. (1990). Basics of qualitative research: Grounded theory procedures and techniques. Newbury Park, CA: Sage Publications, Inc.

Trowler, P. (2008). Cultures and change in higher education: Theories and practice. Basingstoke: Palgrave Macmillan.

Williams, R. T. (2018). Confidence Interventions: Do They Work?. Asian Journal of Humanity, Art and Literature, 5(2), 123-134. https://doi.org/10.18034/ajhal.v5i2.536

Williams, R. T., \& Scott, C. D. (2019). The Current State of Outdoor Learning in a U.K Secondary Setting: Exploring the Benefits, Drawbacks and Recommendations. ABC Journal of Advanced Research, 8(2), 109-122. https://doi.org/10.18034/abcjar.v8i2.537

$--0--$ 